Review

\title{
Open Source Software in the UAE: Opportunities, Challenges and Recommendations (A Survey Research Study)
}

\author{
Manar Abu Talib \\ Department of Computer Science, University of Sharjah, P.O. Box: 27272, Sharjah, UAE
}

Article history

Received: 05-03-2017

Revised: 09-03-2017

Accepted: 19-06-2017

Email: mtalib@sharjah.ac.ae

\begin{abstract}
The UAE is one of the most technologically advanced countries in the Gulf region and the Middle East. IDC expects total IT spending in the UAE to increase at a compound annual growth rate of $6.0 \%$ over the fiveyear forecast period, reaching $\$ 8.06$ billion in 2017 . According to the latest survey by the World Economic Forum: The Global Information Technology Report 2014, the UAE now ranks 24th in the world in terms of IT spending. In this research paper, we look closely at Open Source Software usage in the UAE. A survey study was conducted in four categories-governments and ministries, IT companies, universities and IT enthusiasts to explore the opportunities and challenges faced by this segment of the software industry. The study is also compared with two Arabic countries: KSA and Tunisia. This is the first study of its kind in this part of the world and is expected to contribute significantly to the global direction for Open Source Software.
\end{abstract}

Keywords: Open Source Software, UAE, Governments and Ministries, IT Companies, Universities, IT Enthusiasts

\section{Introduction}

A 2009 survey conducted by International Data Corporation (IDC) found that the Open Source Software (OSS) market has experienced a strong boost from the prevailing economic downturn, with worldwide revenues expected to grow at a $22.4 \%$ compound annual growth rate, reaching $\$ 8.1$ billion by 2013 (Jaspersoft, 2010). This expected growth is also attributed to the increased quality, reliability and support services supplied by OSS providers. In a declining economy, most IT departments are under increased scrutiny and pressure to reduce costs. As a result, many are turning to these providers.

According to Abu Talib et al. (2014), many information systems are proprietary in the UAE. As a result of copy right and licensing issues, they depend on vendors to customize these systems to fit the organization's needs. Most organizations allocate a considerable amount of time and money to software debugging, maintenance and upgrading especially when new functions are added or goals are redefined. Challenged with financial resources, some academic and research organizations have found OSS as alternative for achieving their technological requirements. Moreover, OSS can be valuable for law enforcement agencies and for research and development, defense and legal and justice departments to meet their security and privacy requirements. According to WEBOPEDIA (2015), "Open source developed in the technological community as a response to proprietary software owned by corporations." Our literature survey shows that there is no real OSS development or deployment strategy in place in developing countries similar to those found in developed countries.

\section{Literature Review}

According to Capra et al. (2011), Open source was born as a practical alternative to free software. It becomes as a new approach for many companies to make business upon software. While the role of organizations is clear for commercial OS projects, more study and research are needed for projects based on communities (Capra et al., 2011). The success of Linux and Apache has strengthened the view that the open source paradigm is one of the most promising strategies for enhancing the maturity, quality and efficiency of software development activities (Fuggetta, 2003). Open Source Software (OSS) is defined as software where the source code is available to all users free of charge. It is very often developed in a public, collaborative manner, motivated by an altruistic desire to improve 
society at large: Society comes first and individual commercial interests a distant second. Open source is developed with intention to have better quality, higher reliability, more flexibility, lower cost and an end to predatory vendor lock-in (OSI, 2015). According to Ajila and Wub (2007), an empirical study of the effects of OSS component reuse on software development economics presented interesting results. The researchers specifically examined three economic factors: Cost, productivity and quality and found that "OSS components are of highest quality and that the open source community is not setting a bad example (contrary to some opinion) so far as 'good practices' are concerned." In the UAE, OSS could be a valuable way to avoid total dependence on a single supplier or on foreign providers, further strengthening national security (Abu Talib et al., 2014). It also opens the door to customized applications designed to develop appropriate information systems that best fit the needs of the organization. Moreover, it could support sustainability and provide an opportunity for UAE undergraduate/graduate students, researchers and developers to enhance their programming skills (Abu Talib et al., 2014). As well, it matches the strategic planning goals of UAE in terms of cost-effectiveness and increased access to knowledge. With OSS, managers could experiment with the suitability of business solutions without the cost of license fees. For example, many managers are already turning to enterprise OSS applications as viable sourcing alternatives for databases, data warehouses and enterprise-grade software applications (such as ERP) to reduce costs and increase competitive advantage (Abu Talib et al., 2014). The cost of a desktop computer is not a major issue with OSS, whereas having to obtain valid licenses for commercial software is a real concern. OSS will also eliminate the concept of "cracking" software, since this term has no meaning in the OSS community (Abu Talib et al., 2014).

OSS is not limited to particular research tools, experimental toolkits, or visualization plug-ins. A wide spectrum of system and application software can be envisaged, including programming languages, databases, information rendering and visualization tools, operating systems, applets, business applications, digital forensic tools, simulation tools and privacy and security toolkits (Abu Talib et al., 2014). These applications are also designed to run on tiny mobile phones, enterprise-level database servers and intrusion detection systems (Abu Talib et al., 2014). According to Ullah (2015), many commercial projects nowadays use open-source applications or components. Kilamo et al. (2012) have shown that more and more companies are releasing their proprietary software as open source, forming a software ecosystem of related development projects complemented with a social ecosystem of community members.

\section{Research Design}

The research in this study followed the same structure as the study conducted by King Abdulaziz City for Science and Technology (KACST) in KSA in 2013, which was a collaborative study with IDC (KACST, 2013). We focused on identifying OSS awareness in the UAE, assessing the OSS users' insights in the UAE, exploring OSS opportunities, challenges and recommendations in four categories in the UAE: Governments and ministries (49 participants), IT companies (117 participants), universities (47 participants) and IT enthusiasts (53 participants). The survey had 38 questions, 11 of which were devoted specifically to OSS users/developers. The survey study was followed by interviews with at least four individuals from each category, providing validation of the survey data. Finally, we synthesized the results, provided explanations of possible factors and performed various statistical tests among these four categories (Table 5). There were pilot studies on participants from the University of Sharjah. However, the survey participants were mainly recruited from several decision makers in the governments and ministries category. As for academia, we developed a database for different faculty members from several universities that we got their emails from the universities' websites. As for IT companies and IT enthusiast, we approached them through Linked In. We carried out hypothesis testing for difference in means for difference for each two proportion with the following hypothesis:

Null hypothesis:

$$
H_{0}: p_{1}=p_{2}
$$

Alternative hypothesis (when reject $H_{0}$ ):

$$
H_{1}: p_{1} \neq p_{2}
$$

Rejection criteria:

$$
Z>z_{\alpha / 2} \text { or } Z<-z_{\alpha / 2}
$$

where the test statistic is:

$$
\begin{aligned}
& Z=\frac{\hat{p}_{1}-\hat{p}_{2}}{\sqrt{\hat{p}(1-\hat{p})\left(\frac{1}{n_{1}}+\frac{1}{n_{2}}\right)}} ; \hat{p}_{1}=\frac{X_{1}}{n_{1}}, \hat{p}_{2}=\frac{X_{2}}{n_{2}}, \hat{p}=\frac{X_{1}+X_{2}}{n_{1}+n_{2}} \\
& Z \approx N(0,1) \text { where } p_{1}=p_{2}
\end{aligned}
$$

\section{Results}

Findings from the survey data analysis and the interviews showed more commonalities than differences in the opportunities, challenges and recommendations among the four categories studied. 
Table 1 summarizes the demographic statistics and backgrounds of survey participants in the four categories. It reflects a population sample appropriate for participation in this survey study.

\section{Awareness of OSS in the UAE}

\section{Governments and Ministries}

According to the survey results, there is high awareness of OSS in ministries and government institutions in the UAE. $47 \%$ were frequent users and had good knowledge of OSS, while 35\% were aware but were not frequent users, $12 \%$ were aware but were not users and $6 \%$ reported no knowledge of OSS.

Around $65 \%$ of survey participants had been aware of open-source programming for more than 5 years, while $29 \%$ had heard about it in the past 5 years. $49 \%$ of participants reported using both open-source software and closed-source software. However, $27 \%$ preferred using OSS over closed-source software.
$55 \%$ of survey participants said they trusted OSS programs, while $35 \%$ said they would try the software first. Only $10 \%$ said they did not trust OSS.

$68 \%$ of IT users in ministries and government institutions in the UAE reported that open source programs are excellent and helpful. 16\% of survey participants said OSS is weak and does not rise to expected standards.

In summary, approximately $69 \%$ of IT personnel who work in ministries and governments use OSS, while $31 \%$ do not.

\section{IT Companies}

There is higher awareness of OSS in IT companies than in ministries and government institutions in the UAE. $62 \%$ were frequent users and had good knowledge of OSS, while $31 \%$ were aware of OSS but were not frequent users. $6 \%$ had heard about OSS while only $1 \%$ had no knowledge of it.

Table 1 Summary of Survey Participant Backgrounds

\begin{tabular}{|c|c|c|c|c|}
\hline Survey question & $\begin{array}{l}\text { Governments and } \\
\text { ministries }\end{array}$ & IT companies & Academia & IT enthusiasts \\
\hline What is your highest & $0 \% \mathrm{PhD}$ & $1 \% \mathrm{PhD}$ & $45 \% \mathrm{PhD}$ & $2 \% \mathrm{PhD}$ \\
\hline \multirow[t]{3}{*}{ level of education? } & $37 \%$ Master & $33 \%$ Master & $29 \%$ Master & $13 \%$ Master \\
\hline & $58 \%$ Bachelor & $63 \%$ Bachelor & $24 \%$ Bachelor & $63 \%$ Bachelor \\
\hline & 5\% Diploma & 3\% Diploma & 2\% Diploma & 22\%Diploma/High School \\
\hline \multirow[t]{5}{*}{ What is your age? } & $2 \%(19-23)$ & $3 \%(19-23)$ & $4 \%(19-23)$ & $51 \%(19-23)$ \\
\hline & $22 \%(24-28)$ & $34 \%(24-28)$ & $16 \%(24-28)$ & $37 \%(24-28)$ \\
\hline & $52 \%(29-37)$ & $57 \%(29-37)$ & $29 \%(29-37)$ & $10 \%(29-37)$ \\
\hline & $14 \%(38-45)$ & $5 \%(38-45)$ & $18 \%(38-45)$ & $0 \%(38-45)$ \\
\hline & $10 \%(>45)$ & $1 \%(>45)$ & $33 \%(>45)$ & $2 \%(>45)$ \\
\hline Are you local & $22 \%$ local & $7 \%$ local & $8 \%$ local & $32 \%$ local \\
\hline or resident? & $78 \%$ resident & $93 \%$ resident & $92 \%$ resident & $68 \%$ resident \\
\hline What is your & $96 \%$ employed & $94 \%$ employed & $98 \%$ employed & $96 \%$ employed \\
\hline \multirow[t]{2}{*}{ employment status? } & $2 \%$ unemployed & $4 \%$ unemployed & $2 \%$ unemployed & $2 \%$ unemployed \\
\hline & $2 \%$ retired/housewife & $2 \%$ retired/housewife & $0 \%$ retired/housewife & $2 \%$ retired/housewife \\
\hline $\begin{array}{l}\text { What is your } \\
\text { profession? }\end{array}$ & $\begin{array}{l}\text { IT Managers, senior } \\
\text { software engineers and } \\
\text { IT specialist, software } \\
\text { engineers/ developers/ } \\
\text { programmers }\end{array}$ & $\begin{array}{l}\text { Senior positions, software } \\
\text { engineers, information } \\
\text { security consultants, PHP } \\
\text { programmers, software } \\
\text { developers/designers, } \\
\text { Web developers/designers, } \\
\text { IT professionals, } \\
\text { programmer-analysts, } \\
\text { system analysts, software } \\
\text { consultants, software } \\
\text { quality assurance } \\
\text { engineers, etc. }\end{array}$ & $\begin{array}{l}\text { Professors, IT directors, } \\
\text { IT specialists, } \\
\text { instructors, lab } \\
\text { supervisors }\end{array}$ & $\begin{array}{l}\text { IT and Computer Science } \\
\text { students, biomedical } \\
\text { engineers, communication } \\
\text { engineers, networking } \\
\text { engineers and electrical } \\
\text { engineers }\end{array}$ \\
\hline Do you depend on & $100 \%$ yes & $98 \%$ yes & $100 \%$ yes & $98 \%$ yes \\
\hline $\begin{array}{l}\text { Information } \\
\text { Technology (IT) } \\
\text { on a regular basis? }\end{array}$ & $0 \%$ no & $2 \%$ no & $0 \%$ no & $2 \%$ no \\
\hline Have you ever bought & $57 \%$ don't buy but use & $46 \%$ don't buy but use & $49 \%$ don't buy but use & $49 \%$ don't buy but use \\
\hline programs/applications & $33 \%$ buy sometimes & $45 \%$ buy sometimes & $47 \%$ buy sometimes & $42 \%$ buy sometimes \\
\hline and do they play an & $10 \%$ active shoppers & $6 \%$ active shoppers & $4 \%$ active shoppers & $7 \%$ active shoppers \\
\hline $\begin{array}{l}\text { important role in } \\
\text { your life? }\end{array}$ & $0 \%$ none & $2 \%$ none & $0 \%$ none & $2 \%$ none \\
\hline
\end{tabular}


Around $63 \%$ of survey participants had known about open-source programming for more than 5 years, while $36 \%$ had heard about it in the past 5 years. $57 \%$ of participants preferred to use both open-source and closed-source software, while $35 \%$ preferred to use OSS over closed-source software. IT companies have a higher preference for OSS than respondents in the ministries and governments.

$56 \%$ of survey participants said that they trust Open Source programs, while $32 \%$ preferred to try the software first. Only $12 \%$ said that they do not trust OSS. These numbers are very similar to the results obtained for the ministries and governments.

$83 \%$ of participants from IT companies in the UAE reported that open-source programs are excellent and helpful. This result is higher than in the ministries and governments. $68 \%$ said OSS is excellent. Only $10 \%$ of survey participants from IT companies reported that open-source programs are weak and do not meet accepted standards.
Finally, $76 \%$ of IT personnel who work in IT companies use OSS, while $24 \%$ of them do not.

\section{Academia}

There is also high awareness about OSS in universities in the UAE. $41 \%$ of respondents in this category were frequent users and had good knowledge of OSS, while 38\% knew about OSS but were not frequent users. $17 \%$ had some awareness of OSS while only $4 \%$ knew little or nothing about it. This is the same level of awareness as the category of ministries and governments.

$66 \%$ of survey participants had known about opensource programming for more than 5 years, $30 \%$ for 5 years or less. $60 \%$ of participants reported using both open-source and closed-source software. However, 34\% preferred OSS over closed-source software. This is a higher rate compared to the other categories, which may be due to the considerable cost saving (no license fee) for educational institutions and the fact that students can learn more when they have access to the code of open-source programs and applications.

Table 2. Summary of OSS Awareness in the UAE

\begin{tabular}{|c|c|c|c|c|}
\hline Survey question & Governments and ministries & IT companies & Academia & IT enthusiasts \\
\hline How well do you & $47 \%$ frequent user & $62 \%$ frequent user & $41 \%$ frequent user & $38 \%$ frequent user \\
\hline \multirow[t]{4}{*}{ know about OSS? } & $35 \%$ know but not & $31 \%$ know but not & $38 \%$ know but not & $43 \%$ know but not \\
\hline & & frequent user & frequent user & frequent user \\
\hline & $12 \%$ hear about OSS & $6 \%$ hear about OSS & $17 \%$ hear about OSS & $13 \%$ hear about OSS \\
\hline & $6 \%$ don't know OSS & $1 \%$ don't know OSS & $4 \%$ don't know OSS & $6 \%$ don't know OSS \\
\hline When did you & $65 \%$ (>5 years $)$ & $63 \%$ (>5 years $)$ & $66 \%$ ( $>5$ years $)$ & $62 \%$ ( $>5$ years $)$ \\
\hline \multirow{2}{*}{ hear about OSS? } & $27 \%(<5$ years $)$ & $36 \%(<5$ years $)$ & $30 \%$ (<5 years $)$ & $30 \%$ (<5 years $)$ \\
\hline & $6 \%$ didn't hear about OSS & $1 \%$ didn't hear about OSS & $4 \%$ didn't hear about OSS & $8 \%$ didn't hear about OSS \\
\hline Which type of & $49 \%$ both & $57 \%$ both & $60 \%$ both & $49 \%$ both \\
\hline programs do you & $27 \%$ OSS & $35 \%$ OSS & $34 \%$ OSS & $19 \%$ OSS \\
\hline \multirow[t]{2}{*}{ prefer? } & $16 \% \mathrm{CSS}$ & $6 \% \mathrm{CSS}$ & $2 \% \mathrm{CSS}$ & $11 \% \mathrm{CSS}$ \\
\hline & $8 \%$ don't know & $2 \%$ don't know & $4 \%$ don't know & $21 \%$ don't know \\
\hline Do you trust open & $55 \%$ yes & $56 \%$ yes & $51 \%$ yes & $45 \%$ yes \\
\hline \multirow[t]{2}{*}{ source programs? } & $10 \%$ no & $12 \%$ no & $11 \%$ no & $13 \%$ no \\
\hline & $35 \%$ I have to try first & $32 \%$ I have to try first & $38 \%$ I have to try first & $42 \%$ I have to try first \\
\hline What do you think & $68 \%$ excellent & $83 \%$ excellent & $66 \%$ excellent & $66 \%$ excellent \\
\hline of open source & $16 \%$ weak & $10 \%$ weak & $17 \%$ weak & $8 \%$ weak \\
\hline \multirow[t]{2}{*}{ programs? } & $0 \%$ useless & $0 \%$ useless & $2 \%$ useless & $2 \%$ useless \\
\hline & $16 \%$ don't know & $7 \%$ don't know & $15 \%$ don't know & $24 \%$ don't know \\
\hline Are you a user of open & $69 \%$ yes & $76 \%$ yes & $59 \%$ yes & $66 \%$ yes \\
\hline source software? & $31 \%$ no & $24 \%$ no & $41 \%$ no & $34 \%$ no \\
\hline Which mobile & $72 \%$ Android & $68 \%$ Android & $57 \%$ Android & $60 \%$ Android \\
\hline systems do you & $57 \%$ IOS & $50 \%$ IOS & $57 \%$ IOS & $45 \%$ IOS \\
\hline use more often? & $12 \%$ Windows & $18 \%$ Windows & $32 \%$ Windows & $25 \%$ Windows \\
\hline$*$ checkbox & $2 \%$ Others & $7 \%$ Others & $9 \%$ Others & $8 \%$ Others \\
\hline \multirow{13}{*}{$\begin{array}{l}\text { Pick the programs } \\
\text { you use: } \\
\text { *checkbox }\end{array}$} & $69 \%$ Mozilla FireFox & 78\% Mozilla FireFox & $64 \%$ Mozilla FireFox & 58\% Mozilla FireFox \\
\hline & $80 \%$ Google Android & $62 \%$ Google Android & $72 \%$ Google Android & $70 \%$ Google Android \\
\hline & $16 \%$ Gnome & $20 \%$ Gnome & $9 \%$ Gnome & $13 \%$ Gnome \\
\hline & 14\% Libre/Open Office & 14\% Libre/Open Office & 17\% Libre/Open Office & 19\% Libre/Open Office \\
\hline & $0 \%$ QSM & $0 \%$ QSM & $0 \% \mathrm{QSM}$ & $2 \% \mathrm{QSM}$ \\
\hline & $0 \%$ GNO & $2 \% \mathrm{GNO}$ & $4 \%$ GNO & $0 \%$ GNO \\
\hline & $33 \%$ Linux & $44 \%$ Linux & $28 \%$ Linux & $32 \%$ Linux \\
\hline & $18 \%$ PHP Language & $38 \%$ PHP Language & 28\% PHP Language & 11\% PHP Language \\
\hline & $31 \%$ Apache Server & $45 \%$ Apache Server & $23 \%$ Apache Server & $17 \%$ Apache Server \\
\hline & $8 \%$ Open source data & $21 \%$ Open source & $6 \%$ Open source & 4\% Open source \\
\hline & & data structures & data structures & data structures \\
\hline & $27 \%$ Eclipse IDE & $40 \%$ Eclipse IDE & $40 \%$ Eclipse IDE & $42 \%$ Eclipse IDE \\
\hline & $10 \%$ Other & $25 \%$ Other & $15 \%$ Other & $21 \%$ Other \\
\hline
\end{tabular}


$51 \%$ of survey participants said that they trust Open Source programs, while $38 \%$ would prefer to try the software first. Only $11 \%$ reported that they do not trust OSS.

$66 \%$ of survey participants from the UAE universities thought that open-source programs are excellent and helpful. Only 17\% said open-source programs are weak and not up to standard.

Finally, 59\% of IT people who work in academia use OSS, while $41 \%$ of them do not.

\section{IT Enthusiasts}

The IT enthusiasts' category is not exceptional and the survey results show similarities with the other categories. Table 2 summarizes the awareness level for the four categories studied. Overall, there is high awareness of OSS in the UAE.

\section{OSS Users in the UAE}

Most of the survey participants from the four categories learned about OSS from online resources, online groups and societies and by trying several software applications. 58\% of the participants from academia learned about OSS by reading OSS manuals. When faced with a problem working with a specific OSS application, participants from all four categories search for a solution. Failing to find a solution, they will download another OSS before deciding to remove the current OSS. Participants from the ministries and IT companies found the OSS seminars that they attended useful while the participants from other categories could not say whether these seminars were good enough to learn about OSS. More than $70 \%$ of participants from the ministries, academia and IT enthusiasts are not members of an online community, while $44 \%$ from IT companies stated they are members of an online OSS group. This shows more involvement from this category in the OSS online community and forums. These respondents also have a high rate of attempting to change OSS code $(69 \%)$, followed by the survey participants from the ministries (61\%). Participants from academia reported little interest in changing OSS code, which reveals there are more users than programmers in this category.

Table 3. Summary of OSS users' insights in the UAE

\begin{tabular}{|c|c|c|c|c|}
\hline Survey question & Governments and ministries & IT companies & Academia & IT enthusiasts \\
\hline $\begin{array}{l}\text { How did you learn } \\
\text { about OSS? }\end{array}$ & $\begin{array}{l}58 \% \text { trying and making } \\
\text { mistakes }\end{array}$ & $\begin{array}{l}70 \% \text { trying and } \\
\text { making mistakes }\end{array}$ & $\begin{array}{l}50 \% \text { trying and } \\
\text { making mistakes }\end{array}$ & $\begin{array}{l}62 \% \text { trying and } \\
\text { making mistakes }\end{array}$ \\
\hline \multirow[t]{7}{*}{ *checkbox } & $88 \%$ online resources/ & $83 \%$ online & $88 \%$ online & $94 \%$ online \\
\hline & Tutorials & resources/tutorials & resources/tutorials & resources/tutorials \\
\hline & $61 \%$ online society & $65 \%$ online society & $50 \%$ online society & $53 \%$ online society \\
\hline & $39 \%$ colleague or friend & $29 \%$ colleague or friend & $46 \%$ colleague or friend & $32 \%$ colleague or friend \\
\hline & $45 \%$ reading a manual & $55 \%$ reading a manual & $58 \%$ reading a manual & $41 \%$ reading a manual \\
\hline & $30 \%$ seminars & $35 \%$ seminars & $50 \%$ seminars & $50 \%$ seminars \\
\hline & $0 \%$ Others & $6 \%$ Others & $0 \%$ Others & $6 \%$ Others \\
\hline How do you obtain & $94 \%$ Online & $99 \%$ Online & $96 \%$ Online & $88 \%$ Online \\
\hline open source programs? & $6 \%$ preinstalled on & $17 \%$ preinstalled on & $15 \%$ preinstalled on & $30 \%$ preinstalled on \\
\hline \multirow[t]{5}{*}{ *checkbox } & my laptop, mobile & my laptop, mobile & my laptop, mobile & my laptop, mobile \\
\hline & phone or tablet & phone or tablet & phone or tablet & phone or tablet \\
\hline & $9 \%$ IT service provider & $16 \%$ IT service provider & $15 \%$ IT service provider & $6 \%$ IT service provider \\
\hline & $27 \%$ my workplace & $19 \%$ my workplace & $15 \%$ my workplace & $6 \%$ my workplace \\
\hline & $\begin{array}{l}15 \% \text { copy from someone } \\
0 \% \text { Others }\end{array}$ & $\begin{array}{l}17 \% \text { copy from someone } \\
6 \% \text { Others }\end{array}$ & $\begin{array}{l}15 \% \text { copy from someone } \\
0 \% \text { Others }\end{array}$ & $\begin{array}{l}12 \% \text { copy from someone } \\
0 \% \text { Others }\end{array}$ \\
\hline When you face a & $24 \%$ I remove it & $17 \%$ I remove it & $23 \%$ I remove it & $24 \%$ I remove it \\
\hline problem with an & $79 \%$ I search for solution & $84 \%$ I search for solution & $81 \%$ I search for solution & $82 \%$ I search for solution \\
\hline Open Source Software, & $36 \%$ I download another one & $34 \%$ I download another one & $38 \%$ I download another one & $24 \%$ I download another one \\
\hline *checkbox & $6 \%$ Others & $8 \%$ Others & $4 \%$ Others & $3 \%$ Others \\
\hline Were the seminars & $64 \%$ yes & $54 \%$ yes & $38 \%$ yes & $38 \%$ yes \\
\hline good enough to learn & $9 \%$ no & $21 \%$ no & $4 \%$ no & $6 \%$ no \\
\hline about OSS? & $27 \%$ don't know & $25 \%$ don't know & $58 \%$ don't know & $56 \%$ don't know \\
\hline Are you a member of & $27 \%$ yes & $44 \%$ yes & $23 \%$ yes & $15 \%$ yes \\
\hline $\begin{array}{l}\text { any online social groups } \\
\text { about open source } \\
\text { programming? }\end{array}$ & $73 \%$ no & $56 \%$ no & $77 \%$ no & $85 \%$ no \\
\hline "I've changed the & $43 \%$ strongly agree & $26 \%$ strongly agree & $15 \%$ strongly agree & $24 \%$ strongly agree \\
\hline source code of an & $18 \%$ agree & $43 \%$ agree & $31 \%$ agree & $26 \%$ agree \\
\hline Open Source Program." & $21 \%$ don't know & $18 \%$ don't know & $38 \%$ don't know & $18 \%$ don't know \\
\hline How well do you agree & $9 \%$ disagree & $10 \%$ disagree & $12 \%$ disagree & $17 \%$ disagree \\
\hline with this statement? & $9 \%$ strongly disagree & $3 \%$ strongly disagree & $4 \%$ strongly disagree & $15 \%$ strongly disagree \\
\hline In your opinion, what & $4 \%$ strong & $7 \%$ strong & $6 \%$ strong & $4 \%$ strong \\
\hline is the awareness level & $18 \%$ good & $36 \%$ good & $9 \%$ good & $21 \%$ good \\
\hline \multirow[t]{2}{*}{ about OSS in the UAE? } & $47 \%$ weak & $44 \%$ weak & $64 \%$ weak & $36 \%$ weak \\
\hline & $31 \%$ don't know & $13 \%$ don't know & $21 \%$ don't know & $39 \%$ don't know \\
\hline In your opinion, is open & $18 \%$ goal & $31 \%$ goal & $12 \%$ goal & $6 \%$ goal \\
\hline source program a goal & $67 \%$ tool & $66 \%$ tool & $77 \%$ tool & $91 \%$ tool \\
\hline or a tool? & $15 \%$ don't know & $3 \%$ don't know & $11 \%$ don't know & $3 \%$ don't know \\
\hline
\end{tabular}


Table 4. Summary of OSS Opportunities \& Challenges in the UAE

\begin{tabular}{|c|c|c|c|c|}
\hline Survey question & $\begin{array}{l}\text { Governments and } \\
\text { ministries }\end{array}$ & IT Companies & Academia & IT Enthusiasts \\
\hline \multirow{12}{*}{$\begin{array}{l}\text { Why do you use } \\
\text { open source } \\
\text { programs } \\
\text { ?*checkbox }\end{array}$} & $88 \%$ less cost & $82 \%$ less cost & $73 \%$ less cost & $82 \%$ less cost \\
\hline & $39 \%$ easier to use & $39 \%$ easier to use & $27 \%$ easier to use & $41 \%$ easier to use \\
\hline & $24 \%$ not controlled & $39 \%$ not controlled & $54 \%$ not controlled & $32 \%$ not controlled \\
\hline & by licenses & by licenses & by licenses & by licenses \\
\hline & $18 \%$ high quality & $23 \%$ high quality & $15 \%$ high quality & $18 \%$ high quality \\
\hline & $9 \%$ less bug fix updates & $22 \%$ less bug fix updates & $4 \%$ less bug fix updates & $12 \%$ less bug fix updates \\
\hline & $12 \%$ safe & $18 \%$ safe & $15 \%$ safe & $15 \%$ safe \\
\hline & $27 \%$ vendor independency & $22 \%$ vendor independency & $34 \%$ vendor independency & $24 \%$ vendor independency \\
\hline & $12 \%$ was advised to use & $8 \%$ was advised to use & $23 \%$ was advised to use & $29 \%$ was advised to use \\
\hline & $12 \%$ my company & $8 \%$ my company & $4 \%$ my company & $9 \%$ my company \\
\hline & supports them & supports them & supports them & supports them \\
\hline & $15 \%$ Others & $14 \%$ Others & $12 \%$ Others & $15 \%$ Others \\
\hline \multirow{8}{*}{$\begin{array}{l}\text { What are the } \\
\text { challenges that } \\
\text { you faced when } \\
\text { using open source } \\
\text { programs? } \\
\text { *checkbox }\end{array}$} & $70 \%$ little technical support & $70 \%$ little technical support & $46 \%$ little technical support & $35 \%$ little technical support \\
\hline & $9 \%$ low quality & $5 \%$ low quality & $12 \%$ low quality & $3 \%$ low quality \\
\hline & $21 \%$ requires training & $25 \%$ requires training & $35 \%$ requires training & $32 \%$ requires training \\
\hline & $18 \%$ not available in Arabic & $18 \%$ not available in Arabic & $8 \%$ not available in Arabic & $12 \%$ not available in Arabic \\
\hline & $27 \%$ not safe & $23 \%$ not safe & $15 \%$ not safe & $35 \%$ not safe \\
\hline & $9 \%$ hard & $9 \%$ hard & $0 \%$ hard & $3 \%$ hard \\
\hline & $12 \%$ not flexible & $16 \%$ not flexible & $23 \%$ not flexible & $21 \%$ not flexible \\
\hline & $9 \%$ Others & $12 \%$ Others & $19 \%$ Others & $21 \%$ Others \\
\hline
\end{tabular}

It is clear that most of the participants from all categories believe there is not much awareness of OSS in the UAE, although the survey results proved the opposite. Finally, most agree that OSS is a tool, while a much lower percentage say it should be considered a goal. Table 3 provides more detail about the insights of OSS users in the four categories. In summary, there is no clear bridge among these categories towards improving OSS usage. OSS efforts take place on an individual basis, although there is high awareness and a great deal of OSS implementation in the country.

Further to discussions in the previous section, the most compelling reason for using OSS in the UAE is the cost saving of software not controlled by licenses. Vendor independence is also another advantage affording opportunities to the IT industry in the UAE. Most of those surveyed agreed that lack of technical support, security and training are major challenges facing OSS users in the UAE. Yet, it is interesting to observe that very few participants from all categories deemed the software "low quality" or "hard to use". This reflects the benefits that OSS could provide if more training and technical support were offered. Table 4 illustrates the survey results on OSS opportunities and challenges in the UAE.

\section{Statistical Tests' Analysis}

As stated earlier, findings from the survey data analysis and the interviews showed more commonalities than differences in the opportunities, challenges and recommendations among the four categories studied. In this section, some interesting differences between those groups were reported after we carried out hypothesis testing for difference in means for difference for each two proportion with the following hypothesis:

\section{Null Hypothesis}

There is no difference between the results obtained from the categories:

$$
H_{0}: p_{1}=p_{2}
$$

\section{Alternative Hypothesis (when Reject $H_{0}$ )}

There is a difference between the results obtained from the categories:

$$
H_{1}: p_{1} \neq p_{2}
$$

Sample of statistical tests executed on Table 4 is demonstrated in Table 5. IT company's category showed the highest percentage of OSS users. They are frequent users that they think open source programs are excellent. Interviews with senior participants from this category confirmed this result because they have restricted deadlines and OSS is always a good alternative when they need to meet the market needs. Moreover, this category has the highest online membership in OSS online communities and they strongly believe to adapt OSS as goal where the rest of the groups are far in believing so. In addition, when we interviewed them, there is solid understanding among this group towards establishing national program that pushes OSS movement forward same way in the developed countries.

Although all categories have "little technical support" as the most faced challenge while using OSS, ministries and governments as well as IT company's categories have very high percentage in this regard compared to other categories. This is because they are more 
challenged with real business cases, which have frequent changes that should meet the market needs. As a result, they need to customize/change the code of OSS and they frequently lack technical support. They have to try things themselves and this can take more time and efforts. It is also similar analysis for the difference we got for "was advised to use OSS". It is much less in these two categories due to their high awareness and dealing with several business situations.

\section{Recommendations for Open Source Software in the UAE}

Most survey participants from all categories were very optimistic about the future of OSS. More than $60 \%$ said they thought that OSS has a future in the UAE. 73\% of survey participants from IT companies think that OSS covers the needs of users in the UAE. Most participants reported they would use both OSS and CSS if they were at the head of a company or institute. This result confirms what has been discussed in the previous section. It is to be noted that all categories (except IT companies) do not believe employers take open source into consideration when hiring new employees. Academia and IT enthusiasts do not have a clear sense of the initiatives of the UAE towards OSS, while it is quite clear in the other two categories. According to the survey results, government and social support as well as seminars and workshops are the most effective ways to increase the popularity of OSS in the country.

Moreover, in interviews with participants from ministries and government institutions, most knew of no network or forum for exchanging information about OSS in the UAE. Expectations for such a community included: Providing expertise in the use of OSS, managing and effectively controlling OSS in the country, putting high priority on security, targeting university students, presenting successful case studies of OSS applications to demonstrate the advantages of OSS, establishing procedures and rules to protect the rights of OSS users in the UAE and, finally, working for this community as they engage in their day-to-day professional activities.

Interviews with participants from IT companies suggested having an organizing body that would lead the open-source movement in the UAE and could organize educational events and marketing campaigns. This organizing body should target decision makers and vendors to help them understand the effects of OSS technology on companies and the market and to show how international technology providers that deal with Open Source technology are impacting the UAE. One interviewee comment on this issue was revealing: "I don't think the awareness in the coming years will need such huge organizing bodies, because awareness will happen by itself with time and $30-40 \%$ of organizations are using open source products even without knowing it." A valuable research study by Kilamo et al. (2012) studied the problem of building open-source communities for industrial software originally developed as closed-source. In this research study, supporting processes, guidelines and best practices were discussed and illustrated through an industrial case study.

Table 5. Sample of statistical tests executed on Table 4

\begin{tabular}{|c|c|c|c|c|c|c|c|c|c|c|}
\hline & $1-2$ & $1-3$ & $1-4$ & $2-3$ & $2-4$ & $3-4$ & $\begin{array}{l}Z \text { max, } \\
\text { absolute } \\
\text { value }\end{array}$ & $\begin{array}{l}\mathrm{Z} \text { min, } \\
\text { absolute } \\
\text { value }\end{array}$ & $\begin{array}{l}\text { Result } \\
{[-z ;+z]} \\
5 \% \\
\end{array}$ & $\begin{array}{l}\text { Result } \\
{[-z ;+z]} \\
2 \% \\
\end{array}$ \\
\hline \multicolumn{11}{|c|}{ Why do you use open source programs? } \\
\hline Less cost & 0.7782 & 1.451 & 0.7068 & -0.882 & 0 & 0.9198 & 1.451010 & 0.881708 & yes & yes \\
\hline Easier to use & 0 & 0.994 & -0.171 & 1.088 & 0.1882 & 1.2678 & 1.267789 & 1.088404 & yes & yes \\
\hline Not controlled by licenses & -1.5054 & 02.46 & -0.749 & 1.2619 & -0678 & -1.934 & 1.261938 & 2.456167 & yes & yes \\
\hline High quality & -0.5681 & 0.312 & 0 & -0.878 & -0.577 & 0.3432 & 0.343184 & 0.877606 & yes & yes \\
\hline Less bug fix updates & -1.7206 & 0.802 & -0.41 & 02.604 & -1.267 & 1.2647 & 1.264911 & 2.604344 & yes & yes \\
\hline Safe & -0.7782 & -0.34 & -0368 & -0.341 & -0.376 & 0 & 0.000000 & 0.375584 & yes & yes \\
\hline Vendor independency & 0.5242 & -0.58 & 0.2878 & 1.0986 & 0.2187 & -0.941 & 1.098619 & 0.940721 & yes & yes \\
\hline Was advised to use & 0.5949 & -1.1 & -1.81 & 1.6538 & 2.4862 & 0.5817 & 2.486151 & 1.809604 & no & no \\
\hline My company supports them & 0.5949 & 1.182 & 0.409 & -0.744 & 0.1646 & 0.8649 & 1.181746 & 0.743768 & yes & yes \\
\hline Others & 0.1284 & 0.339 & 0 & -0.25 & 0.1307 & 0.3728 & 0.372822 & 0.250452 & yes & yes \\
\hline \multicolumn{11}{|c|}{ What are the challenges that you faced when using open source programs? } \\
\hline Little technical support & 0 & 1.914 & 3.131 & -2.059 & -3.439 & -0.957 & 3.131007 & 3.438999 & no & no \\
\hline Low quality & 0.649 & -0.37 & 1.0578 & 0.9924 & -0.482 & -1.471 & 1.057828 & 1.471330 & yes & yes \\
\hline Requires training & -0.4342 & -1.2 & -1.052 & 0.8996 & 0.7126 & -0.27 & 0.899632 & 1.199194 & yes & yes \\
\hline Not available in Arabic & 0 & 1.181 & 0.7035 & -1.328 & -0.79 & 0.5669 & 1.180814 & 1.328122 & yes & yes \\
\hline Not safe & 0.417 & 1.16 & -0.727 & -0.878 & 1.2168 & 2.014 & 2.014035 & 0.877606 & no & yes \\
\hline Hard & 0 & 1.834 & 1.0578 & -2.268 & -1.229 & 1.0552 & 1.833750 & 2.267787 & no & yes \\
\hline Not flexible & -0.5303 & -1.1 & -1.025 & 0.7221 & 0.5895 & -0.205 & 0.722143 & 1.104570 & yes & yes \\
\hline Others & -0.4502 & -1.1 & -1.433 & 0.7851 & 1.1046 & 0.2122 & 1.104556 & 1.432520 & yes & yes \\
\hline
\end{tabular}

*1. Governments and ministries

*2. IT companies

*3. Academia

*4. IT enthusiasts 
Interviewees from academia offered a number of suggestions such as beginning with the education sector by educating students about OSS, developing a top-down approach, having a platform to refer to and closing the gap between academia and industry. According to interviewees in this group, OSS use is more prevalent in the Western world than in the Arab world because of the lack of skilled and trained professionals who are fully aware of OSS features and advantages. Software testing and security approval procedures are also needed.

Interviewees from the IT enthusiasts category said they were not aware of any network for OSS information exchange for Arab developers. They also agreed that it is important to use forums and groups to enrich the OSS community. They would like to see efforts in raising awareness, holding seminars and workshops, incorporating OSS applications, providing alternatives to replace CSS and providing opportunities for the younger generation to become involved. In using OSS, interviewees in the IT enthusiast group stated their role is to explore OSS and use it as a tool to enhance applications. They reported using OSS for university projects or personal use.

In summary, all participants from all categories agreed on the importance of having an OSS community in the country for developers and users. The community role should include improving applications and tools and being very supportive, active and always available. According to Bosua et al. (2014), in OSS communities, the impressions members have about each other are expected to play an important role in fostering effective collaboration. The researchers highlighted the peer impression formation process among OSS participants in terms of perceived expertise, trustworthiness, productivity, pooling experience and other factors that make collaboration easy or difficult. Another valuable study by Sowe et al. (2008) explained the altruistic sharing of knowledge between knowledge providers and knowledge seekers in Developer and User mailing lists using the Debian project as a case study. The methodology they propose could be adapted to study the knowledge sharing activities of OSS projects through posting and replying in similar mailing lists. Thus, the knowledge sharing activities in OSS projects are clearer. Finally, Midhaa and Palviab (2012) discussed the success factors for OSS project overtime that should be taken into consideration. Briefly, they indicated that user base, language translations, responsibility assignment and modularity positively impact OSS success.

\section{Comparison Study with KSA and Tunisia}

According to Abu Talib (2015), there are significant OSS efforts in the UAE and KSA, but the vision for OSS in the GCC region is not yet clear. According to interviewees as well as survey participants from both countries, OSS is widely used in many organizations and companies. However, there is no official authority or organizing body to unite these efforts-even though, as shown by the OSS opportunities presented in this study, such efforts could contribute significantly to sustainable development in the region. Nevertheless, according to the comparison results, the adoption of open source is improving and the challenges will diminish over time. According to Alarifi (2013), more than two third of the Saudi Community are not aware of OSS technologies. As a result, they are working to develop the core of the OSS ecosystem in Saudi Arabia and suggesting the following action items:

- $\quad$ National OSS Strategy

- Government to adopt OSS solutions

- Several pilot projects

- Development of useful OSS software

- Joining the global community to enhance OSS solutions

The UAE case study also highlighted the road map and offered specific recommendations.

On the other hand, Tunisia has clearer OSS vision in the region.

The Tunisian strategy in the field of Information Technology and Communication dedicates a special interest to Open Source Software as a technical and technological alternative to be considered in new or redesigning system's projects (MCT, 2015). In July 2001, the Government of Tunisia defined a Free and Open Source Software (FOSS) policy (Lewis, 2010). The objectives included encouraging migration to FOSS, including FOSS in school curricula, providing incentives to FOSS company start-ups and ensuring that public procurement policies are not biased against FOSS (Lewis, 2010). The Ministry of Communication Technologies is also involved in establishing several initiatives, conventions, frameworks and agreement such as (MCT, 2015):

- International Telecommunication Union (ITU) to create the first OSS canter in the Arab world, which will be based in Tunisia

- Marseille-Provence Technopole at Chateau Gombert in France, aiming at benefiting enterprises operating in Open Source Software

- SYSTEM@TIC PARIS-REGION in France to facilitate the extension of company OSS activities in both countries

The following figure shows the OSS statistics in Tunisia (Tunisian OSS Unit, 2015). 
This comparison study clarifies the OSS movement and shows the promising results for the future of OSS in the Arab region. It draws the road map for other Arab countries; taking into consideration the research study of the UAE ending with developing a national program, having the government support and establishing a support OSS canter as it is in Tunisia

\section{Conclusion}

In the UAE, now ranks 24th in the world in terms of IT spending (UAEITR, 2013; WEFGITR, 2015), Open Source Software can play a vital role in avoiding total dependence on a single vendor and attendant licensing problems. Our research study showed that there is no real OSS development or deployment strategy in place in the UAE that compares with those found in developed countries. We took an in-depth look at the use of Open Source Software in the UAE. A survey study was conducted in four categories (governments and ministries, IT companies, universities and IT enthusiasts) to explore the opportunities and challenges faced by this segment of the software industry. Moreover, a comparison study was investigated with two Arabic countries: KSA and Tunisia.

\section{Acknowledgment}

The author wishes to thank the Graduate Studies Office at University of Sharjah for its generous funding of this research project. We are also grateful to the research assistants from the University: Anfal Hassan, Balsam AlKouz, RandaAbuAli and ArwaYahya, for their valuable contribution in the survey study as well as for their help in conducting the interviews.

\section{Ethics}

The author declares that there is no ethical issues that may arise after the publication of this manuscript.

\section{Biographies}

Research interest includes software engineering with substantial experience and knowledge in conducting research in software measurement, software quality, software testing, ISO 27001 for Information Security and Open Source Software. Manar is also working on ISO standards for measuring the functional size of software and has been involved in developing the Arabic version of ISO 19761 (COSMIC-FFP measurement method). She published more than 40 refereed conferences, journals, manuals and technical reports, involved in more than 200 professional activities and sponsored research activities and supervised 30 capstone projects. She received the Best Teacher Award two times, the
Exemplary Faculty Award in 2008 and 2010, Google CS4HS Award in 2014, QCRI ArabWIC and Anita Borg Institute Faculty scholarships in 2015, outstanding University and Community Service Award in 2016 and Exemplary Leader Award in WiSTEM 2016. She was the Counselor of IEEE Student Branch at Zayed University, 2012-2013 and founder and former CEO of Emirates Digital Association for Women (EDAW111). She is the ArabWIC VP of Chapters in Arab Women in Computing Association (ArabWIC), an executive member in UAE IEEE Section, the Sharjah Google Developer Group Manager, the UAE representative for the COSMIC-FPP Education Committee and the International Collaborator to Software Engineering Research Laboratory in Montreal, Canada..

\section{References}

Abu Talib, M., 2015. Towards sustainable development through open source software in GCC. Proceedings of the IEEE International Symposium on Signal Processing and Information Technology, Dec. 7-10, IEEE Xplore Press, pp: 52-56. DOI: $10.1109 /$ ISSPIT.2015.7394391

Abu Talib, M., M. AbuOdeh, A. Almansoori and A. AlNauimi, 2014. Enhancing social science research in the UAE: An open source software solution University of Sharjah (UOS) case study. J. Comput. Sci., 11: 98-108. DOI: $10.3844 /$ jessp.2015.98.108

Ajila, S.A. and D. Wub, 2007. Empirical study of the effects of open source adoption on software development economics. J. Syst. Software, 80: 1517-1529. DOI: 10.1016/j.jss.2007.01.011

Alarifi, A., 2013. National program for free and open source technologies Saudi Arabia. King Abdulaziz City for Science and Technology (KACST).

Bosua, A., J. Carvera, R. Guadagnob, B. Bassette and D. McCallumc et al., 2014. Peer impressions in open source organizations: A survey. J. Syst. Software, 94: 4-15. DOI: 10.1016/j.jss.2014.03.061

Capra, E., C. Francalancia, F. Merloa and C. RossiLamastrab, 2011. Firms' involvement in Open Source projects: A trade-off between software structural quality and popularity. J. Syst. Software, 84: 144-161. DOI: 10.1016/j.jss.2010.09.004

Fuggetta, A., 2003. Open source software-an evaluation. J. Syst. Software, 66: 77-90.

DOI: 10.1016/S0164-1212(02)00065-1

Jaspersoft, 2010. The state of enterprise open source software after the oracle acquisition of sun Microsystems. Jaspersoft Report.

KACST, 2013. Enhancing innovatons through free/open source software in KSA. King Abdulaziz City for Science and Technology. 
Kilamo, T., I. Hammouda, T. Mikkonen and T. Aaltonen, 2012. From proprietary to open sourceGrowing an open source ecosystem. J. Syst. Software, 85: 1467-1478. DOI: $10.1016 /$ j.jss.2011.06.071

Lewis, J.A., 2010. Government open source policies.

MCT, 2015. Tunisian open source software unit. Ministry of Communication Technologies.

Midhaa, V. and P. Palviab, 2012. Factors affecting the success of open source software. J. Syst. Software, 85: 895-905. DOI: 10.1016/j.jss.2011.11.010

OSI, 2015. Open source initiative.

Sowe, S.K., I. Stamelos and L. Angelis, 2008. Understanding knowledge sharing activities in free/open source software projects: An empirical study. J. Syst. Software, 81: 431-446.

DOI: $10.1016 /$ j.jss.2007.03.086
UAEITR, 2013. United Arab Emirates information technology report Q1.

Ullah, N., 2015. A method for predicting open source software residual defects. Software Quality J., 23: 55-76. DOI: 10.1007/s11219-014-9229-3

'WEBOPEDIA',

2015. http://www.webopedia.com/TERM/O/open_source. html

WEFGITR, 2015. World economic forum: The Global Information Technology Report. 